\title{
DESIGN, INOVAÇÃO E SUSTENTABILIDADE: ESTUDO DA RECICLAGEM DE PRODUTOS MULTI-MATERIAIS POLIMÉRICOS SEM SEPARAÇÃO PRÉVIA
}

\section{ELISA GUERRA ASHTON EICHENBERG | UFRGS}

PALAVRAS-CHAVE: Design de produto. Seleção de materiais. Produtos multi-materiais. Sustentabilidade. Inovação.

O presente estudo trata de temas relacionados à seleção de materiais e ao design de produto frente às questões ambientais. A evolução no uso dos materiais ao longo dos anos acompanha o nosso desenvolvimento como sociedade (ASHBY, 2011), o maior exemplo dessa colocação são as denominações dos períodos históricos: Idade da Pedra, Idade do Bronze, Idade do Ferro etc. Atualmente, entende-se que já se superou a Idade dos Polímeros e aproxima-se da Idade dos Compósitos e Multi-materiais. Isso se dá, dentre outros fatores à popularização e diversificação dos materiais poliméricos nas últimas décadas somada ao desenvolvimento tecnológico e ao maior rigor nos requisitos do projeto. Essa situação converge para a tendência de desenvolvimento de produtos com diferentes materiais em um mesmo componente, os chamados multi-materiais (THOMAS; YANG, 2009). As principais razões para o desenvolvimento desses produtos consistem em: meIhorar a performance de um componente, integrar mais funções a um material, reduzir os custos operacionais e facilitar a produção, além de evitar partes muito volumosas (WARGNIER et al., 2014).

Apesar das vantagens técnicas, os multi-materiais são causadores de impactos ambientais negativos, já que apresentam dificuldades de reciclagem, decorrentes da complexidade na separação dos seus materiais. Os processos de reciclagem tradicionais que possibilitam o gerenciamento do ciclo fechado (WORRELL; REUTER, 2014) e da logística reversa (LEITE, 2009) geralmente dependem da separação dos materiais (MANZINI; VEZZOLI, 2002). Não sendo possível a separação eficiente, o reprocessamento dos polímeros misturados apresenta dificuldades como a obtenção de uma mistura homogênea, devido às diferenças de ponto de fusão e viscosidade, além da presença de contaminantes como pigmentos, por exemplo (GOODSHIP, 2007; LA MANTIA; SCAFFARO, 2014). Cabe salientar ainda que o reprocessamento é apenas a primeira barreira a ser vencida, uma vez que polímeros misturados reciclados apresentam propriedades desconhecidas, o que dificulta sua reinserção no ciclo produtivo. Assim, se faz necessária ainda a busca por aplicações para esse novo material reciclado, para que o mesmo possa integrar as cadeias de reciclagem e ser reinserido no mercado.

A dificuldade de reciclagem e reaplicação dos multi-materiais gera acúmulo de resíduos sólidos poliméricos, causando impactos ambientais negativos. O tempo prolongado de decomposição dos polímeros faz com que esses materiais ocupem espaço por muito tempo em aterros sanitários, esgotando a capacidade dos mesmos. Outro problema é relativo ao risco de incêndios acidentais com altos índices de emissão de gases poluentes, pois nos casos em que há muito material polimérico no aterro sanitário esse risco aumenta. Além disso, alguns polímeros são frequentemente complementados com aditivos como cargas, plastificantes, pigmentos etc. Esses aditivos podem conter metais tóxicos, substâncias extremamente prejudiciais ao meio ambiente e à saúde da população (AGUADO; SERRANO, 1999).

Sabe-se que solução ideal para esse problema consiste na adoção das premissas do ecodesign desde as fases iniciais da concepção dos produtos (MANZINI; VEZZOLI, 2002). A aplicação do Design for Disassembly (DfD ou Design para a Desmontagem) e do Design for Recycling (DfR ou Design para a Reciclagem) são alternativas viáveis para minimizar os impactos ambientais negativos causados pelos multi-materiais a longo prazo (ASHBY, 2001). Destaca-se, entretanto, que os riscos associados aos problemas ambientais precisam de soluções urgentes (WORLD ECONOMIC FORUM, 2017). Assim, na presente pesquisa discute-se, através de revisão bibliográfica e de estudos práticos, a possibilidade de desenvolvimento de soluções a curto prazo para esse problema. 
O objetivo consiste em estudar a reciclagem de produtos multi-materiais, sem separação prévia, visando a utilização do material resultante em novas aplicações com valor agregado. Para tanto, apresenta-se uma revisão bibliográfica e dois estudos práticos (Estudo Prático A e Estudo Prático B). O Estudo Prático A envolve a reciclagem de escovas de dente multi-materiais através do processo de micronização. Posteriormente o material resultante é caracterizado por microscopia eletrônica de varredura (MEV), teste de densidade, ensaio de tração e análise térmica dinâmico-mecânico (DMA). Apresenta-se ainda a seleção de potenciais áreas de aplicação para o novo material reciclado, por meio de Mapas de Propriedades de Materiais e teste de viabilidade da aplicação selecionada. No Estudo Prático B utilizam-se duas amostras com granulometrias distintas, para avaliar a influência do tamanho das partículas do material reciclado. $\mathrm{Na}$ etapa de caracterização, além dos ensaios conduzidos no Estudo $A$, realiza-se ainda distribuição granulométrica, ensaio de dureza, calorimetria exploratória diferencial (DSC) e análise termogravimétrica (TGA).

Os resultados demonstraram a viabilidade técnica de se promover a reciclagem de escovas de dente multi-materiais por meio do processo de reciclagem mecânica tradicional sem separação prévia. O material reciclado apresensintético para produção de calçados e componentes. $\mathrm{Na}$ avaliação da influência do tamanho das partículas, constatou-se que não houve influência significativa no material resultante. Destaca-se ainda como contribuição e tecnológica deste estudo a proposição de uma alternativa tecnicamente viável para a reciclagem de produtos teoricamente "não-recicláveis", contribuindo com a redução da geração de resíduos sólidos.

\section{REFERÊNCIAS}

AGUADO, J.; SERRANO, D. Feedstock Recycling of Plastic Wastes. Royal Society of Chemistry: Cambridge, 1999.

ASHBY, M. F. Drivers for material development in the 21st century. Progress in Materials Science. 46:191199, 2001.

ASHBY, M. F. Materials Selection in Mechanical

Design. Oxford: Elsevier, 2011.

GOODSHIP, V. Introduction to Plastics Recycling, Second Edition. Shrewsbury: Smithers Rapra Publishing, 2007.

LA MANTIA, F. P.; SCAFFARO, R. Recycling Polymer Blends. In Utracki, L. A.; Wilkie, C. A. (eitores). Polymer Blends Handbook, Chapter 20, p. 1885, 2014. DOI 10.1007/978-94-007-6064-6_23.

LEITE, P. R. Logística Reversa: Meio ambiente e competitividade. 2 ed. São Paulo: Prendice Hall, 2009.

MANZINI, E.; VEZZOLI, C. O Desenvolvimento de Produtos Sustentáveis - Os requisitos ambientais dos produtos industriais. São Paulo: Edusp, 2002.

THOMAS, S.; YANG, W. Advances in Polymer Processing: From Macro To Nano Scales. Cambridge: Woodhead Publishing, 2009.

WARGNIER, W.; KROMM, F. X.; DANIS, M.; BRÈCHET, Y. Proposal for a multi-material design procedure. Materials and Design. 56:44-49, 2014. DOI 10.1016/j. matdes.2013.11.004.

WORLD ECONOMIC FORUM. Global Risks Report, 2017. Disponível em: http://reports.weforum.org/global-risks-2017/ Acessado em: 05.03.2017.

WORRELL, E.; REUTER, M. (editors) Handbook of Recycling: State-of-the-art for practioners, analysts and scientist. Elsevier: Oxford, 2014. 